\title{
Microbial mechanisms of tolerance to weak acid stress
}

\section{Nuno P. Mira* and Miguel C. Teixeira}

Biological Sciences Research Group, Department of Bioengineering, Institute for Biotechnology and Bioengineering, Instituto Superior Técnico, Universidade de Lisboa, Lisbon, Portugal

${ }^{*}$ Correspondence: nuno.mira@ist.utl.pt

Edited by:

Thomas E. Hanson, University of Delaware, USA

Keywords: carboxylic acids, weak acid food preservatives, response and resistance to weak acid stress, food-borne spoilage microbes, tolerance to weak acids

Carboxylic acids are ubiquitous molecules found in microbial metabolic pathways and that have been explored for a wide array of applications including food preservation (e.g., acetic, propionic, benzoic, and sorbic acids), chemotherapy (e.g., the analgesic acetylsalicylic acid, the immunosuppressor mycophenolic acid or the antimalarial drugs artesunic and artemisinic acids) or agriculture (e.g., the herbicides 2,4-dichlorophenoxyacetic acid). This research topic contributes to the understanding of the molecular mechanisms underlying adaptation to weak acid stress in microbes [extensively reviewed in Piper et al. (2001); Boot et al. (2002); Cotter and Hill (2003); Smits and Brul (2005); Mollapour et al. (2008); Teixeira et al. (2011)], a knowledge base that impacts the fields of Medicine, Health, Food Safety, and the Environment.

The exploitation of carboxylic acids as "building-block molecules" for chemical synthesis has recently been a hot topic of research, accompanying the orientation of US and EU policy towards the development of biorefineries(Sauer et al., 2008; Abbott et al., 2009). To be economically sustainable biomassbased refineries must efficiently produce biofuels, but must also produce effective alternatives to the oil-derivatives that are used today as precursors/catalysts by the chemical industry. The carboxylic group, along with other functional groups frequently found in carboxylic acids, make these molecules attractive platforms for chemical synthesis and/or catalysis. The efforts put by the scientific community to develop efficient processes for large-scale production of carboxylic acids from renewable carbon sources, exploring different microbes as cell factories, have led to significant improvements (Sauer et al., 2008; Abbott et al., 2009); however, the yield of microbial carboxylic acid production is still limited. This low yield is mainly caused by to the toxic effects of the acids in the producing cells and by the diversion of substrate towards metabolites other than the acid of interest. The article of Jarboe et al. (2013) reviews the toxic effects exerted by, and the underlying adaptive responses to, lipophilic carboxylic acids in Saccharomyces cerevisiae and Escherichia coli, two host systems that have been exploited as cell factories. Within the same context, Steiger et al. (2013) review the most recent findings regarding biosynthesis of itaconic acid in Aspergillus terreus as well as the metabolic- and genetic engineering-based strategies attempted to improve the yield of production of this acid in this fungus and in other hosts.

The ability of microbial pathogens to colonize the human body is frequently dependent on their ability to tolerate carboxylic acids. This the case of probiotic bacteria that need to tolerate the presence of bile salts (composed by bile acids conjugated with glycine or taurine) to colonize the gut, or of Candida species that need to cope with acetic and lactic acids in the vaginal tract, produced by the bacteria that co-colonize that niche. Ruiz et al. (2013) review the main adaptive responses of probiotic Lactobacilli and Bifidobacteria to cope with the toxic effect exerted by bile salts and by bile. Several reports on adaptive mechanisms to weak acids in Candida are featured as well. The involvement of the multidrug (MDR) transporter of the Major Facilitator Superfamily (MFS) CgAqr1 in C. glabrata tolerance to acetic acid and to the antifungal drugs flucytosine and clotrimazole is herein demonstrated (Costa et al., 2013). The involvement of the HOG1-signalling pathway, controlled by the Hog1 protein kinase, in C. glabrata tolerance and response to sorbic acid is described by Jandric et al. (2013). Sorbic acid is widely used as a preservative in over-the-counter vaginal products and therefore the identification of genes/proteins involved in C. glabrata resistance to this compound is detrimental to improve the efficacy of those products and, consequently, to control infections caused by this pathogenic yeast.

Weak carboxylic acids (e.g., acetic, propionic, sorbic and benzoic acids) are important food preservatives and spoilage microbes must overcome their presence to grow in food products. Much of what is known today regarding the mechanisms underlying tolerance and resistance to weak acid food preservatives in spoilage Fungi, particularly at a genome-wide scale, was gathered in the experimental eukaryotic model yeast Saccharomyces cerevisiae, itself a spoilage yeast (Piper et al., 2001; Mollapour et al., 2008; Mira et al., 2010). Two studies dedicated to S. cerevisae responses to weak acid stress are included in this research topic. The review of Giannattasio et al. (2013) focuses on the equilibrium between the activation of pro-survival or pro-death mechanisms described to occur in acetic acid-stressed yeast cells. The second study, undertaken by Ullah et al. (2013), shows that under extreme weak acid stress S. cerevisiae cells prefer to preserve energy reserves thus limiting the activation of energy-consuming adaptive mechanisms (such as the activity of the plasma membrane proton pump). Results from Ullah et al. also reinforce a previous hypothesis that yeast cells adapt to weak acid stress by modifying the cell envelope to reduce the diffusion rate of the undissociated acid to the intracellular environment (Simoes et al., 2006; Mira et al., 2009). The study of Diakogiannis et al. (2013) shows that this mechanism of diffusional restriction is also relevant for protection against weak acid toxicity in the food-borne pathogen Listeria monocytogenes. The response of Campylobacter jejuni, also a food-borne pathogen, to formic acid is the scope 
of the study performed by Kassem et al. (2013). Formic acid has been used as a feed additive to reduce emergence of $C$. jejuni in chickens, the primary reservoir of this pathogen. However, the data obtained suggest that formic acid might act as an inducer (or at least a positive modulator) of entry of $C$. jejuni cells into a viable-but-not-culturable (VBNC) state that allows these bacterial cells to become untraceable. The development of a $\mathrm{pH}$ sensitive fluorescent probe to monitor the internal $\mathrm{pH}$ of Bacillus subtillis cells is the goal of the study of Van Beilen and Brul (2013). Using this newly developed probe the authors demonstrate that germination of $B$. subtillis spores involves a prominent increase in internal $\mathrm{pH}$ up to 7 (Van Beilen and Brul, 2013). In the presence of inhibitory concentrations was not altered of sorbic acid in the extracellular milieu reduced the germination rate and abrogated the increase in internal $\mathrm{pH}$, while no significant effect was registered under acetic acid stress (Van Beilen and Brul, 2013). It thus seems that sorbic acid is more suited to prevent contamination of food products with $B$. subtillis than acetic acid.

Altogether this research topic highlights the importance of pursuing the in-depth study of the molecular mechanisms underlying the toxicity and resistance to weak organic acids as an important way to contribute for the development of more appropriate tools for the control and elimination of food-borne pathogens/contaminants that thrive in acidic environments and for the engineering of optimized strains to be used as superior cell factories, able to tolerate inhibitory weak acid concentrations, among other fermentation-related stresses.

\section{ACKNOWLEDGMENTS}

All the reviewers that actively participated in the peer-review of the articles published within the scope of this research topic are acknowledge for their valuable contributions.

\section{REFERENCES}

Abbott, D. A., Zelle, R. M., Pronk, J. T., and Van Maris, A. J. (2009). Metabolic engineering of Saccharomyces cerevisiae for production of carboxylic acids: current status and challenges. FEMS Yeast Res. 9, 1123-1136. doi: 10.1111/j.15671364.2009.00537.x

Boot, I. R., Cash, P., and O’byrne, C. (2002). Sensing and adapting to acid stress. Antonie Van Leeuwenhoek 81, 33-42. doi: 10.1023/A:1020565206835

Costa, C., Henriques, A., Pires, C., Nunes, J., Ohno, M., Chibana, H., et al. (2013). The dual role of Candida glabrata drug:H+ antiporter CgAqr1 (ORF CAGL0J09944g) in antifungal drug and acetic acid resistance. Front. Microbiol. 4:170. doi: $10.3389 /$ fmicb.2013.00170

Cotter, P. D., and Hill, C. (2003). Surviving the acid test: responses of grampositive bacteria to low pH. Microbiol. Mol. Biol. Rev. 67, 429-453. doi: 10.1128/MMBR.67.3.429-453.2003

Diakogiannis, I., Berberi, A., Siapi, E., Arkoudi-Vafea, A., Giannopoulou, L., and Mastronicolis, S. K. (2013). Growth and membrane fluidity of foodborne pathogen Listeria monocytogenes in the presence of weak acid preservatives and hydrochloric acid. Front. Microbiol. 4:152. doi: 10.3389/fmicb.2013. 00152

Giannattasio, S., Guaragnella, N., Zdralevic, M., and Marra, E. (2013). Molecular mechanisms of Saccharomyces cerevisiae stress adaptation and programmed cell death in response to acetic acid. Front. Microbiol. 4:33. doi: $10.3389 /$ fmicb. 2013.00033
Jandric, Z., Gregori, C., Klopf, E., Radolf, M., and Schuller, C. (2013). Sorbic acid stress activates the Candida glabrata high osmolarity glycerol MAP kinase pathway. Front. Microbiol. 4:350. doi: 10.3389/fmicb.2013.00350

Jarboe, L. R., Royce, L. A., and Liu, P. (2013). Understanding biocatalyst inhibition by carboxylic acids. Front. Microbiol. 4:272. doi: 10.3389/fmicb.2013.00272

Kassem, I. I., Chandrashekhar, K., and Rajashekara, G. (2013). Of energy and survival incognito: a relationship between viable but non-culturable cells formation and inorganic polyphosphate and formate metabolism in Campylobacter jejuni. Front. Microbiol. 4:183. doi: 10.3389/fmicb.2013.00183

Mira, N. P., Lourenco, A. B., Fernandes, A. R., Becker, J. D., and Sá-Correia, I. (2009). The RIM101 pathway has a role in Saccharomyces cerevisiae adaptive response and resistance to propionic acid and other weak acids. FEMS Yeast Res. 9, 202-216. doi: 10.1111/j.1567-1364.2008.00473.x

Mira, N. P., Teixeira, M. C., and Sá-Correia, I. (2010). Adaptive response and tolerance to weak acids in Saccharomyces cerevisiae: a genome-wide view. OMICS 14, 525-540. doi: 10.1089/omi.2010.0072

Mollapour, M., Shepherd, A., and Piper, P. W. (2008). Novel stress responses facilitate Saccharomyces cerevisiae growth in the presence of the monocarboxylate preservatives. Yeast 25, 169-177. doi: 10.1002/ yea. 1576

Piper, P., Calderon, C. O., Hatzixanthis, K., and Mollapour, M. (2001). Weak acid adaptation: the stress response that confers yeasts with resistance to organic acid food preservatives. Microbiology 147, 2635-2642.

Ruiz, L., Margolles, A., and SNchez, B. (2013). Bile resistance mechanisms in Lactobacillus and Bifidobacterium. Front. Microbiol. 4:396. doi: 10.3389/fmicb.2013.00396

Sauer, M., Porro, D., Mattanovich, D., and Branduardi, P. (2008). Microbial production of organic acids: expanding the markets. Trends Biotechnol. 26, 100-108. doi: 10.1016/j.tibtech.2007.11.006

Simoes, T., Mira, N. P., Fernandes, A. R., and Sá-Correia, I. (2006). The SPI1 gene, encoding a glycosylphosphatidylinositol-anchored cell wall protein, plays a prominent role in the development of yeast resistance to lipophilic weak-acid food preservatives. Appl. Environ. Microbiol. 72, 7168-7175. doi: 10.1128/AEM.01476-06

Smits, G. J., and Brul, S. (2005). Stress tolerance in fungi - to kill a spoilage yeast. Curr. Opin. Biotechnol. 16, 225-230. doi: 10.1016/j.copbio.2005.02.005

Steiger, M. G., Blumhoff, M. L., Mattanovich, D., and Sauer, M. (2013). Biochemistry of microbial itaconic acid production. Front. Microbiol. 4:23. doi: 10.3389/fmicb.2013.00023

Teixeira, M. C., Mira, N. P., and Sá-Correia, I. (2011). A genome-wide perspective on the response and tolerance to food-relevant stresses in Saccharomyces cerevisiae. Curr. Opin. Biotechnol. 22, 150-156. doi: 10.1016/j.copbio.2010.10.011

Ullah, A., Chandrasekaran, G., Brul, S., and Smits, G. J. (2013). Yeast adaptation to weak acids prevents futile energy expenditure. Front. Microbiol. 4:142. doi: 10.3389/fmicb.2013.00142

Van Beilen, J. W., and Brul, S. (2013). Compartment-specific pH monitoring in Bacillus subtilis using fluorescent sensor proteins: a tool to analyze the antibacterial effect of weak organic acids. Front. Microbiol. 4:157. doi: $10.3389 /$ fmicb. 2013.00157

Received: 13 December 2013; accepted: 18 December 2013; published online: 30 December 2013.

Citation: Mira NP and Teixeira MC (2013) Microbial mechanisms of tolerance to weak acid stress. Front. Microbiol. 4:416. doi: 10.3389/fmicb.2013.00416

This article was submitted to Microbial Physiology and Metabolism, a section of the journal Frontiers in Microbiology.

Copyright (c) 2013 Mira and Teixeira. This is an open-access article distributed under the terms of the Creative Commons Attribution License (CC BY). The use, distribution or reproduction in other forums is permitted, provided the original author(s) or licensor are credited and that the original publication in this journal is cited, in accordance with accepted academic practice. No use, distribution or reproduction is permitted which does not comply with these terms. 